\title{
Effect of Substrate Temperature on the Structure and the Metal Insulator Transition in Pulsed laser deposed $\mathrm{VO}_{2}$ Films on Soda Lime glass
}

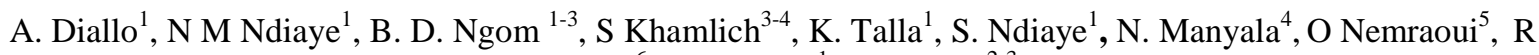 \\ Madjoe $^{6}$, A. C. Beye ${ }^{1}$, M. Maaza ${ }^{2-3}$ \\ ${ }^{1-}$ Laboratoire de Photonique et de Nano-Fabrication, Faculté des sciences et Techniques Université Cheikh Anta Diop de Dakar (UCAD) \\ B.P. 25114 Dakar-Fann Dakar (Senegal). \\ ${ }^{2-}$ UNESCO-UNISA Africa Chair in Nanosciences-Nanotechnology, College of Graduate Studies, University of South Africa, Muckleneuk \\ ridge, PO Box 392, Pretoria-South Africa, \\ ${ }^{3-}$ Nanosciences African Network (NANOAFNET), iThemba LABS-National Research Foundation of South Africa, 1 Old Faure road, Somerset West 7129, \\ Western Cape, South Africa \\ ${ }^{4-D e p a r t m e n t ~ o f ~ P h y s i c s, ~ S A R C H I ~ C h a i r ~ i n ~ C a r b o n ~ T e c h n o l o g y ~ a n d ~ M a t e r i a l s, ~ I n s t i t u t e ~ o f ~ A p p l i e d ~ M a t e r i a l s, ~ U n i v e r s i t y ~ o f ~ P r e t o r i a, ~}$ \\ Pretoria, South Africa. \\ ${ }^{5-}$ Mechatronics, Cape Peninsula University of Technology, P O Box 1906, Bellville, 7530, South Africa. \\ ${ }^{6-}$ Department of Physics, University of the Western Cape, Cape Town, South Africa.
}

\begin{abstract}
In this paper, we report the effect of soda lime substrate deposition temperature $\left(\mathrm{T}_{\mathrm{s}}\right)$ on the crystal structure and the metal insulator transition of $\mathrm{VO}_{2}$ thin films. Samples were deposited at substrate deposition temperature ranging from 450 to $600{ }^{0} \mathrm{C}$ by pulsed-laser deposition and characterized by x-ray diffraction and UV-VIS spectrophotometer. At a substrate temperature of $550^{\circ} \mathrm{C}$, the $\mathrm{VO}_{2}$ (100) reflection dominate the spectrum showing a change in crystalline grains orientation. The highest transition temperatures of $74{ }^{\circ} \mathrm{C}$ with the lowest hysteresis width of $11{ }^{\circ} \mathrm{C}$ were obtained on the same sample grown at a substrate deposition temperature of 500 ${ }^{\circ} \mathrm{C}$ and also corresponding to the largest grains size of a value of $350 \mathrm{~nm}$.
\end{abstract}

\section{Keywords}

Crystal growth; Grains Growth; Texturation; Phase transition; Pulsed Laser deposition;

Corresponding author:

\section{Abdoulaye DIALLO MsC}

Laboratoire de Photonique et de Nano-Fabrication, Faculté des sciences et Techniques Université Cheikh Anta Diop de Dakar (UCAD) B.P. 25114 Dakar-Fann Dakar (Senegal).

Tel: 00221775779586

E-mail: abdoulayediallosn@gmail.com 


\section{Introduction}

Vanadium dioxide $\left(\mathrm{VO}_{2}\right)$ has attracted much attention in recent years because it is well known to have a temperature driven metal to insulator transition (MIT) around a critical temperature $\left(\mathrm{T}_{\mathrm{MIT}}\right)$ of $68^{\circ} \mathrm{C}$ [1]. This MIT is accompanied by a transformation of crystallographic structure, from monoclinic at temperatures below $\mathrm{T}_{\text {MIT }}$ to tetragonal at temperatures above $\mathrm{T}_{\text {MIT. }}$. This first order phase transformation is characterized by a small lattice distortion along the c-axis, which results in pairing of the vanadium atoms and a distinct band structure in each phase. In the insulating phase, a monoclinic distortion of the lattice by a pairing of the $\mathrm{V}$ atoms induces a change in the V-O hybridization, resulting in a rise of the $\pi^{*}$ band above the Fermi energy and a splitting of the $\mathrm{d}_{/ /}$band with one above and the other below the Fermi level. The optical band gap between the $\mathrm{d}_{/ /}$valence and $\pi^{*}$ conduction bands is obtained as $0.7 \mathrm{eV}$ in the insulating phase, to which the $\pi^{*}-d_{/ /}$correlation energy contributes partially. Contrary, in the metallic phase $\mathrm{d}_{/ /}$and $\pi^{*}$ are the lowest-energy bands near the Fermi level and they overlap $[1,2]$. The phase transition behaviors of deposited $\mathrm{VO}_{2}$ films are often investigated for practical use. The transition temperature and the hysteresis width are generally the criteria qualifying of deposited $\mathrm{VO}_{2}$ material. A lower phase transition temperature is favorable for device applications such as smart window [3]. The narrow hysteresis films width $\left(1-5{ }^{0} \mathrm{C}\right)$ implies good switching properties and can be used for IR radiation control in smart windows, and also in light modulators, etc..., and a broad hysteresis width is for optical data storage $[4,5]$. In terms of the energy efficiency, and because of its, as mentioned promising technological applications for IR radiation control, this thermochromic $\mathrm{VO}_{2}$ compound has sparked a large research effort especially in its thin film configuration. Many efforts have been undertaken to deposit suitable $\mathrm{VO}_{2}$ thin films by reactive sputtering, pulsed laser ablation, evaporation, chemical vapor deposition techniques, oxidation of deposited metal films and sol-gel techniques [6-11]. In addition to a requirement for an accurate optimization to obtain the correct $\mathrm{VO}_{2}$ polycrystalline structure due to the multiple $\mathrm{V}$ electronic valences and its high affinity with oxygen [12-13], it is challenging to synthesize large thermochromic $\mathrm{VO}_{2}$ based coatings, with such techniques. While the cost effective sol-gel synthesized $\mathrm{VO}_{2}$ coatings exhibit a relatively good IR modulation, they do not possess long term age stability. The excellent agreement between theory and experiments has yielded strong evidence for efficient growth control of metal oxide nanostructures; it has also produced great expectation for the future development of nano-materials devices and the optimization of their physical properties. Moreover, when the thermodynamic stabilization is achieved, not only is the size tailored but also the shape as well as crystallographic structure maybe controlled. This controlled crystallographic structure has an important bearing and quite often modifies the physical properties of materials. In the high quality single 
crystalline form of $\mathrm{VO}_{2}$ the MIT occurs at the critical temperature of $340 \mathrm{~K}$ and has a narrow hysteresis, but in physical vapor deposited (PVD) films the critical temperature, the width of the hysteresis loop, and the amplitude of the MIT depend strongly on the film morphology and stoichiometry as well as structural defects. PVD films showing good thermochromic properties are usually grown as $\mathrm{VO}_{2}(\mathrm{R})$ at around $600{ }^{\circ} \mathrm{C}$. A. Ilinski et al [14] reported, the metal- semiconductor phase transition depend on the grain size and exhibit a hysteresis $\left(20-30{ }^{\circ} \mathrm{C}\right.$ ) in the polycrystalline films. R. Lopez et al [15], report the enhanced hysteresis (greater than $35{ }^{\circ} \mathrm{C}$ ) in the semiconductor-to-metal phase transition of $\mathrm{VO}_{2}$ precipitates formed in $\mathrm{SiO}_{2}$ by ion implantation. Te-Wei Chiu et al [16], reported that it has been proven the single crystal substrates is effective to obtain $\mathrm{VO}_{2}$ thin films with a narrow hysteresis width but they are expensive and difficult to prepare on large scale.

This communication reports on the synthesis of a-axis oriented and nanosized $\mathrm{VO}_{2}$ at different substrate temperature by pulsed laser deposition (PLD) on soda lime glass substrate without any catalyst. To our knowledge, soda-lime glass is used in everyday products and devices such as solar cells, household mirrors, automobile glass, and architectural building windows. Therefore, ours focus investigation is an interesting topic in thin film growth for optical application in a cost effective way as the physical properties of the films will depend strongly on their texturation.

\section{Experimental details}

The films were deposited on the substrate held at temperatures ranging from 450 to $600{ }^{\circ} \mathrm{C}$ at deposition time of $45 \mathrm{~min}$. A KrF excimer laser, wavelength of $248 \mathrm{~nm}$, fluence of $1.7 \mathrm{~J} / \mathrm{cm}^{2}$, repetition rate of $10 \mathrm{~Hz}$, was incident on target of pure $\mathrm{V}$ metal. The soda lime-target distance was kept at $65 \mathrm{~mm}$. The cooling temperature soda lime was done with $50^{\circ} \mathrm{C} / \mathrm{min}$. The deposition was carried out in an oxygen atmosphere at a pressure $15 \mathrm{mTor}$. X-ray diffraction (XRD) patterns using an AXS Bruker diffractometer equipped with a position sensitive detector determined the crystalline structure. The films morphology was characterized via scanning electron microscopy (SEM). The metal insulator transition was investigated in the wavelength of ultraviolet-visible-near infrared region using a CECIL 2000 spectrophotometer incorporated with Peltier thermoelectric heating and cooling stage. The light source, detector and sample holder are designed to fit within a dark box that has a cover. The spectrophotometer was allowed to create a baseline which removes background from the data to be collected. The beam of light is directed to the sample and the detector detects the amount of light transmitted through the sample. The data was generated and captured by the computer and temperature measurements were recorded. The data collected was used in our work for to study the metal insulator transition. 


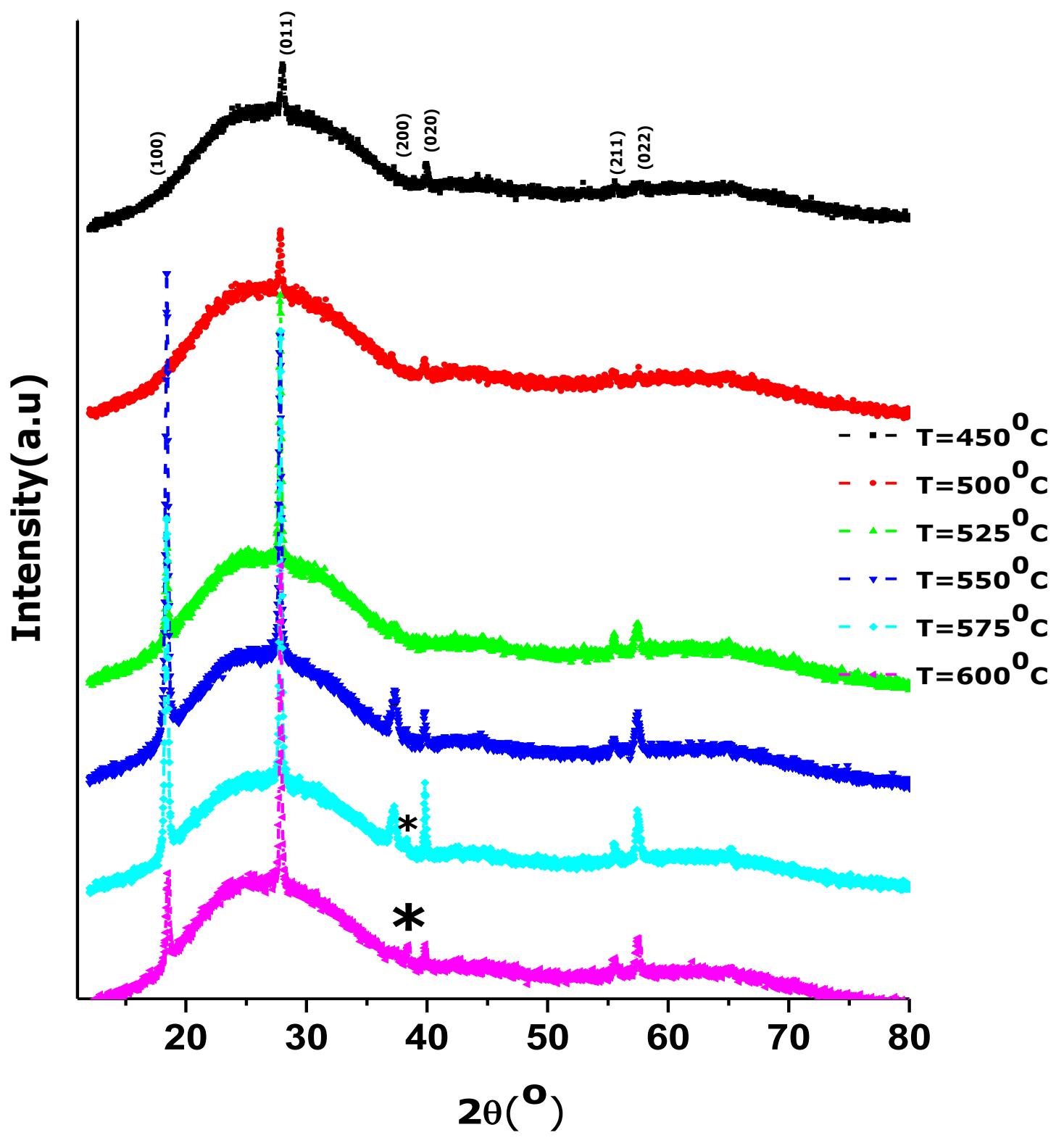

Fig.1: $\quad \mathrm{XRD}$ of $\mathrm{VO}_{2}$ monoclinic (JCPDS 43-1051) thin films deposed by pulsed laser deposition on glass at different substrate deposition temperatures $\left(\mathrm{T}_{\mathrm{S}}\right)$.

\section{Results and discussion}

The XRD profile of the $\mathrm{VO}_{2}$ thin films deposited on soda lime glass substrate at different substrate deposition temperatures (Ts) is shown in Fig 1. The prominent Bragg reflections are occurring around $2 \theta=18.42^{\circ}$ and 
$2 \theta=27.08^{\circ}$ corresponding respectively to (100) and (011) diffraction planes, along with four other weak diffraction peaks viz. (200), (020), (211), (211) which confirms the monoclinic $\mathrm{VO}_{2}$ polycrystalline nature of the film (JCPDS 0043-1051). Fig 1. Shows that the $\mathrm{VO}_{2}$ (011) reflection emerges from a broad structure. The broad structure may suggest the existence of a disordered phase of $\mathrm{VO}_{2}$. The XRD spectra of the films deposited at substrate deposition temperatures of above $500{ }^{\circ} \mathrm{C}$ exhibited the same behaviour as that of the film deposited at below $500{ }^{\circ} \mathrm{C}$ with an additional Bragg reflection at $2 \theta=18.42^{\circ} \mathrm{C}$, corresponding to $\mathrm{VO}_{2}(100)$ reflection of the $\mathrm{VO}_{2}$ monoclinic phase. At a substrate deposition temperatures below and above $550^{\circ} \mathrm{C}$, the grains are preferentially oriented along the $\mathrm{VO}_{2}(011)$ reflection, but for the specific substrate deposition temperature of $550^{\circ} \mathrm{C}$, the $\mathrm{VO}_{2}(100)$ reflection dominate the spectrum showing a change in crystalline grains orientation. The appearance of this new $\mathrm{VO}_{2}(011)$ reflection is a clear indication of the deterioration of the orientation of the crystalline $\mathrm{VO}_{2}$ grains with an increase in temperature.

Compared with the standard data, the relative intensity of (100) reflection (ref: Fig.2a), of the $\mathrm{VO}_{2}$ thin films reaches a maximum at the temperature of $550{ }^{\circ} \mathrm{C}$, indicating that the as-obtained $\mathrm{VO}_{2}(100)$ plane is most probably the preferred growth direction of the $\mathrm{VO}_{2}(\mathrm{M} 1)$ nano-grains at a substrate deposition temperature of $550{ }^{\circ} \mathrm{C}$.

In addition to the $\mathrm{VO}_{2}(100)$ Bragg reflection which appears within the increase of the substrate deposition temperature, the patterns of the films deposited at temperature higher than $550{ }^{\circ} \mathrm{C}$, show the emergence of a new Bragg reflection at $2 \theta=38.23^{\circ}$, which was identified and attributed as the (0006) reflection of $\mathrm{V}_{2} \mathrm{O}_{3}$ by $\mathrm{Zhou}$ et al. in their work [17]. However, a qualitative phase analysis (search match), using the PANAlytical X'pert Highscore Plus software with the ICDD PDF database has showed that the only closest phase that could probably much the peak indicated by $*$ is $\mathrm{Na}_{1.80} \mathrm{~V}_{2} \mathrm{O}_{5}$ (400) (JCPDS 0020-1167). Therefore we could speculate that this reflection at $2 \Theta=38.23^{\circ}$ also could indicate the presence of small amount of $\mathrm{Na}_{1.80} \mathrm{~V}_{2} \mathrm{O}_{5}$ phase in the thin films on soda-lime glass substrates, resulting from a diffusion of $\mathrm{Na}^{+}$into thin films from substrates at high substrate temperature. It is interesting to note that this small impurity does not affect the thermochromic properties of the $\mathrm{VO}_{2}$ films. S. Lu et al. [18], reported the same-like impurity with two small peaks at angle of $2 \theta=12.1^{\circ}$ and $2 \theta=29.1^{\circ}$ indicating the presence of small amount of $\mathrm{Na}_{x} \mathrm{~V}_{2} \mathrm{O}_{5}$ phase in the films on soda-limesilica glass substrates, which resulted from the diffusion of Na into the films. Wang Xue-Jin et al: [19], strongly concluded that sodium ions would diffuse from soda-lime substrate to film surface when sputter performed at high substrate temperature $\left(580^{\circ} \mathrm{C}\right.$ in their experiment), which was in agreement with other authors who claimed that $\mathrm{VO}_{2}$ film could not be deposited on soda-lime glass because of sodium contamination. Therefore we could 


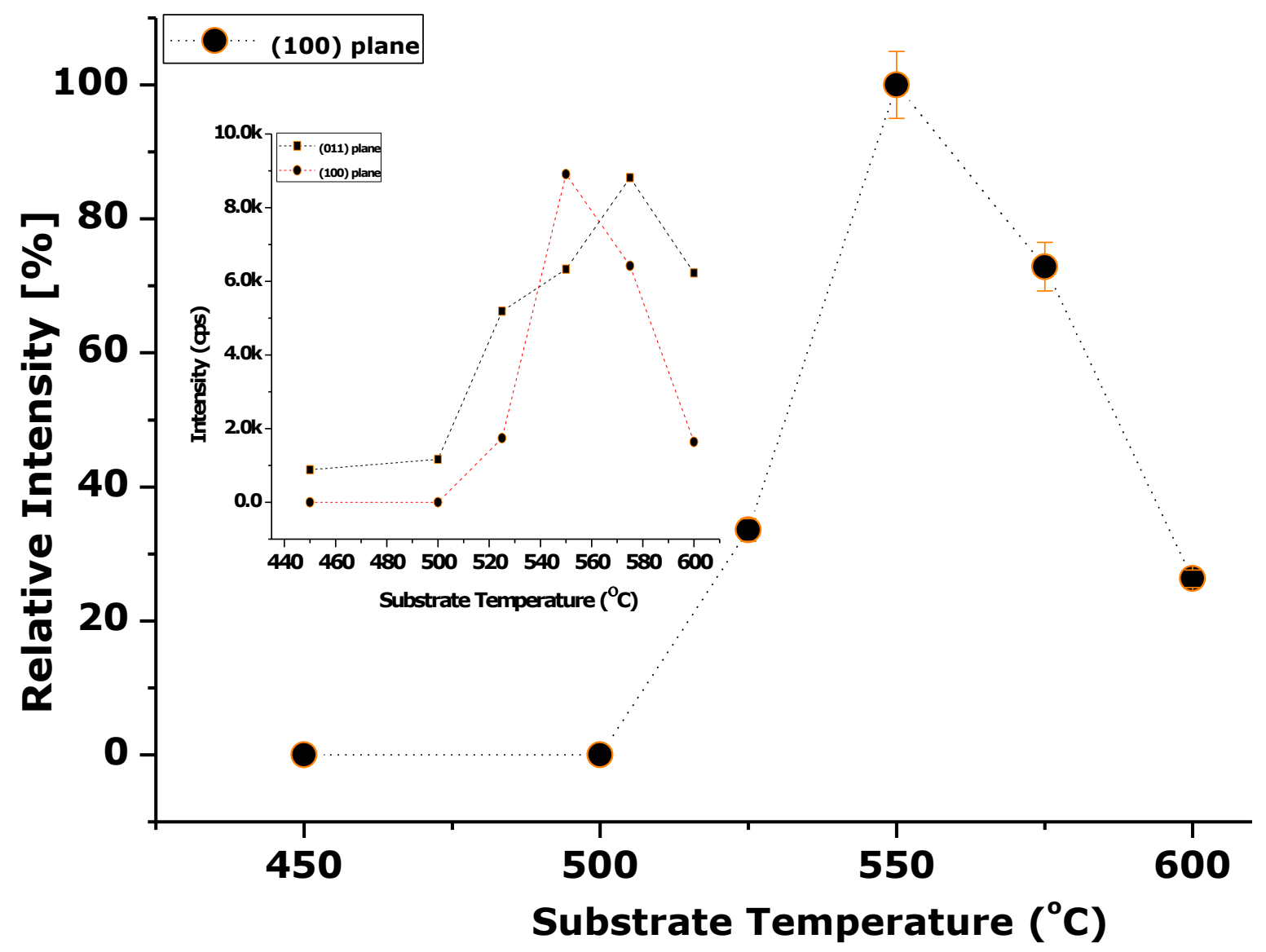

Fig.2a: $\quad$ Relative Intensity of the (100) reflection of $\mathrm{VO}_{2}$ with respect to the (011) plane of pulsed laser deposed $\mathrm{VO}_{2}$ thin films as function of substrate deposition temperature. Inset: evolution of the intensity of both reflections as function of substrate deposition temperature.

suggest that at a substrate temperature of $575^{\circ} \mathrm{C}$ and beyond, the peak at $2 \Theta=38.23^{\circ}$ indicate the presence of $\mathrm{Na}_{1.80} \mathrm{~V}_{2} \mathrm{O}_{5}$ phase in the thin films on soda-lime glass substrates, and is resulting from a diffusion of $\mathrm{Na}^{+}$into thin films from substrates high substrate temperature.

Figure $2 \mathrm{~b}$ shows the influence of deposition temperature on the $\mathrm{VO}_{2}$ crystallites along $\mathrm{VO}_{2}(011)$ plane, which correlates well with the influence of the deposition temperature on the intensity of the peak $\mathrm{VO}_{2}(011)$. Fig.2c report on the evolution of the d-spacing as function of the substrate deposition temperatures, it can be seen that the effect of the deposition temperature is the same on both $\mathrm{VO}_{2}(011)$ and (100) planes, the increase in 


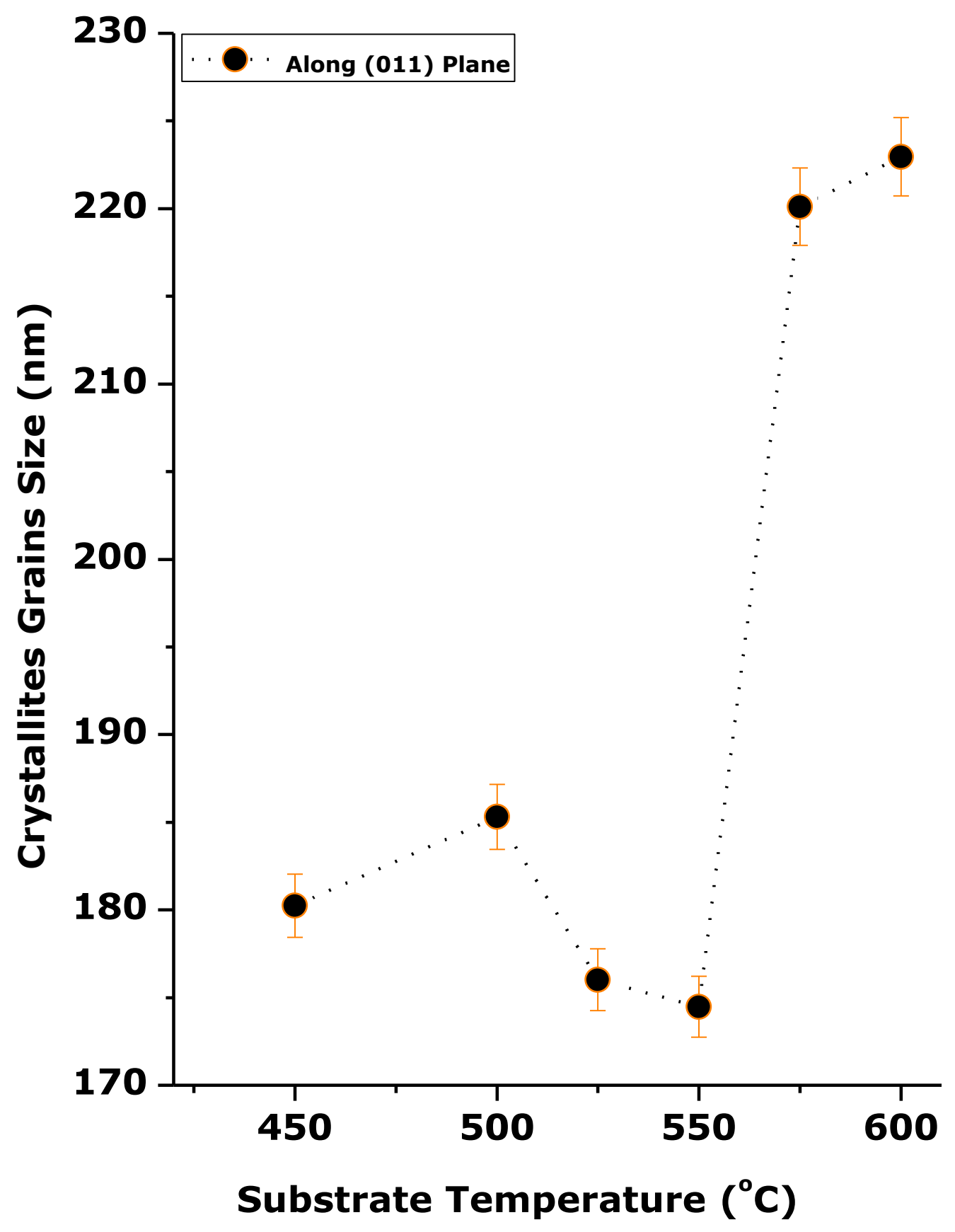

Fig.2b:

Crystallites size along (011) plane of pulsed laser deposed $\mathrm{VO}_{2}$ thin films as function of substrate deposition temperature 


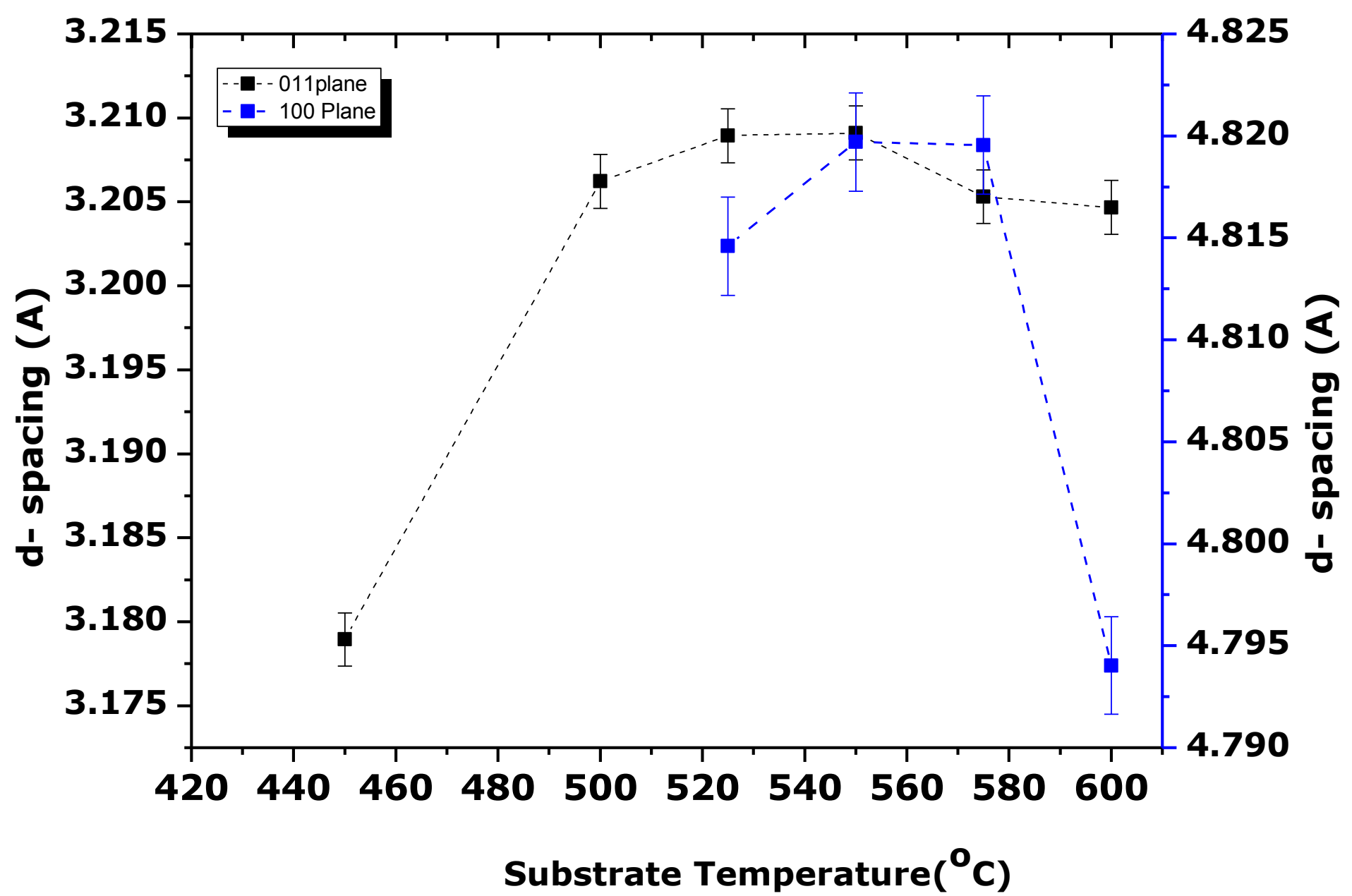

Fig.2c:

Evolution of the d-spacing along the $\mathrm{VO}_{2}(011)$ and $\mathrm{VO}_{2}(100)$ of pulsed laser deposed $\mathrm{VO}_{2}$ thin films as function of substrate deposition temperature.

substrate temperature induced an increase in d-spacing from $450{ }^{\circ} \mathrm{C}$ to $550{ }^{\circ} \mathrm{C}$ before dropping down. It can be noted that the $\mathrm{d}_{(100)}$-spacing dropped four time faster than that of the $\mathrm{d}_{(011)}$-spacing at a substrate temperature of $550{ }^{\circ} \mathrm{C}$ and beyond. We suggest that this can be due to the substrate thermal treatment around it transition temperature of $575^{\circ} \mathrm{C}$.

To investigate the effect on grain size thermo-optical properties and the metal insulator phase transition in $\mathrm{VO}_{2}$ films deposited on soda lime, the transmittance measurements were carriedwhile heating and cooling the sample 

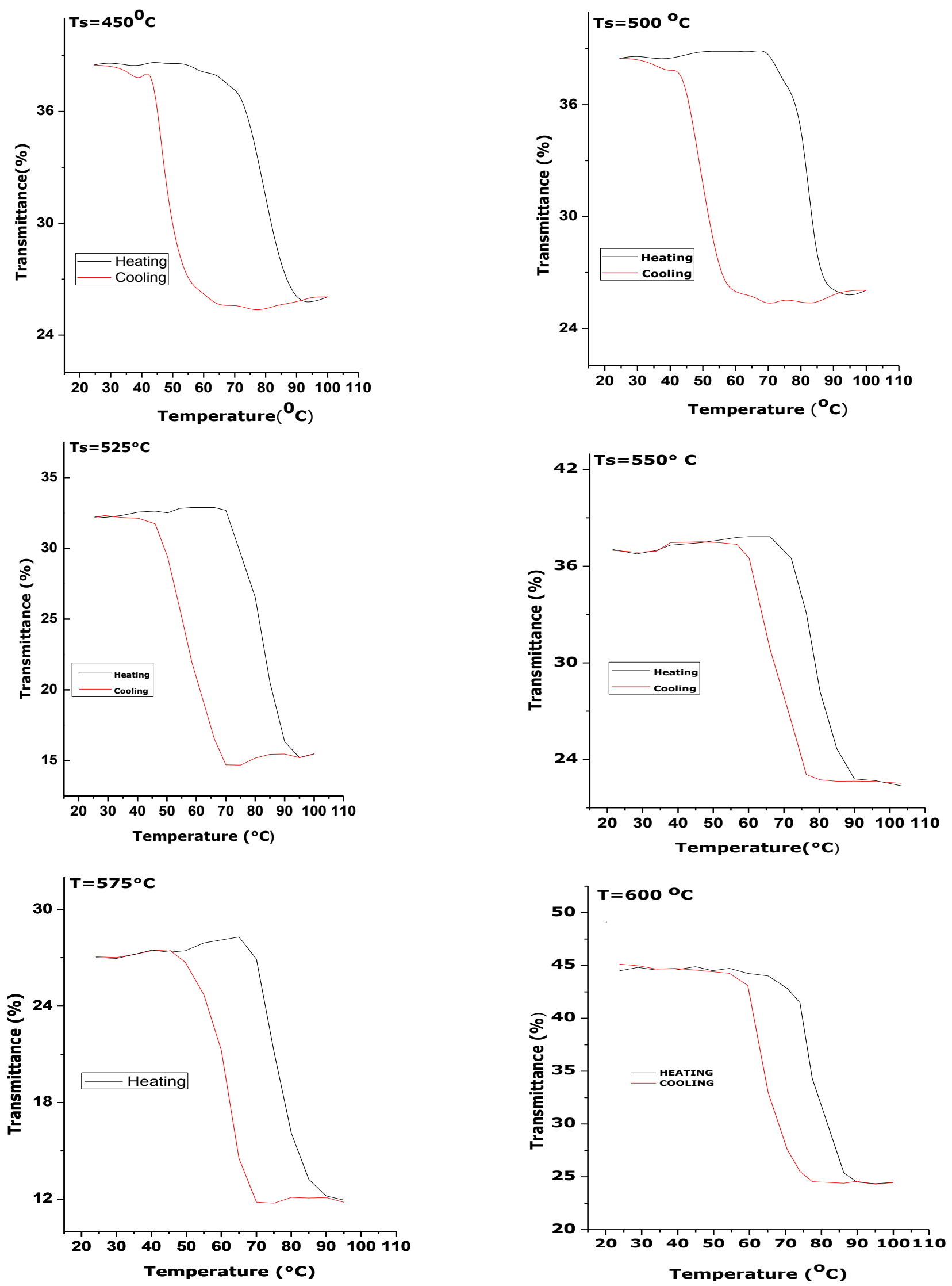

Fig.3a:

Thermal hysteresis loops of transmittance at wavelength of $1100 \mathrm{~nm}$ of pulsed laser deposed $\mathrm{VO}_{2}$ thin films as function of substrate deposition temperature. 

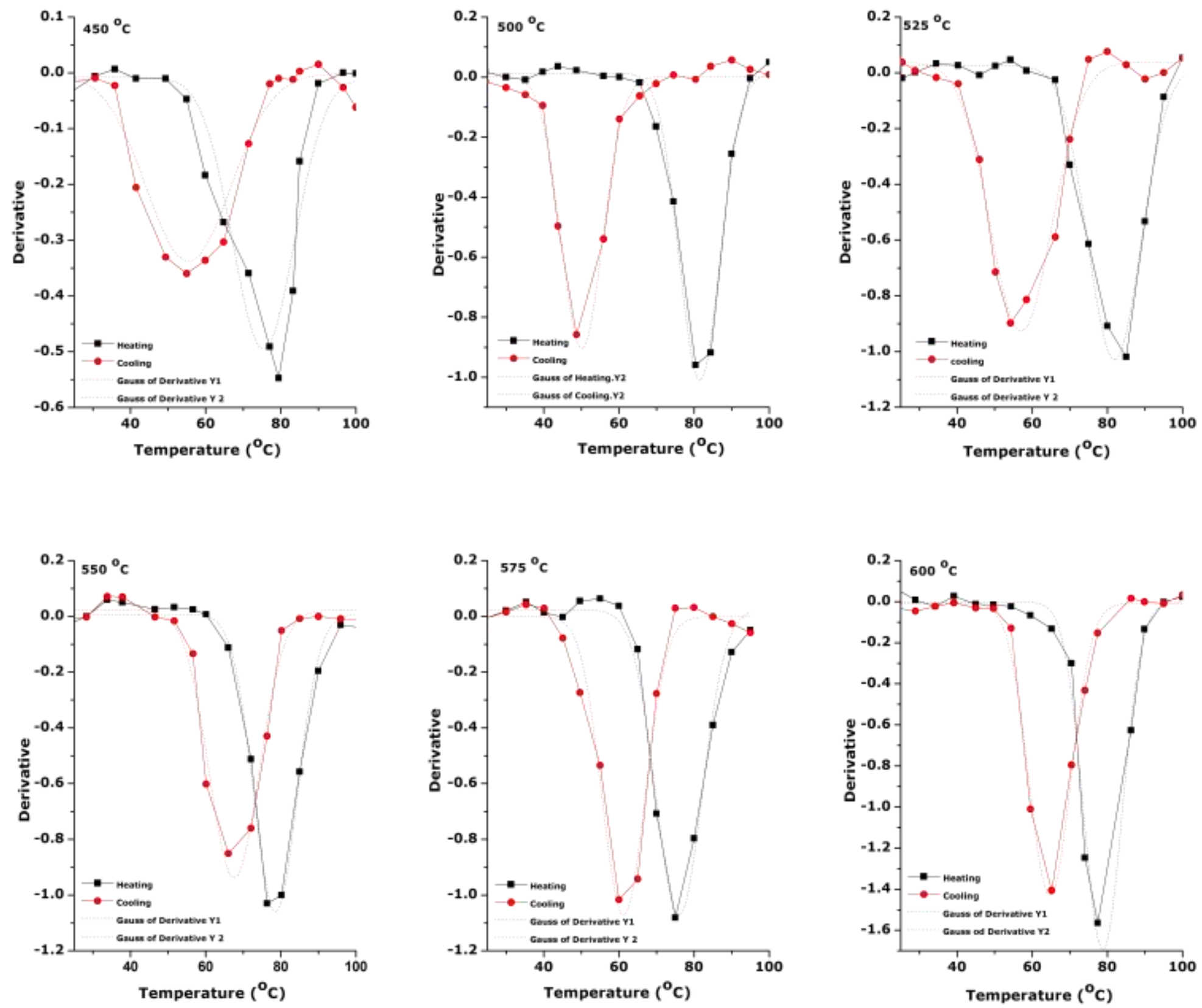

Fig.3b: 


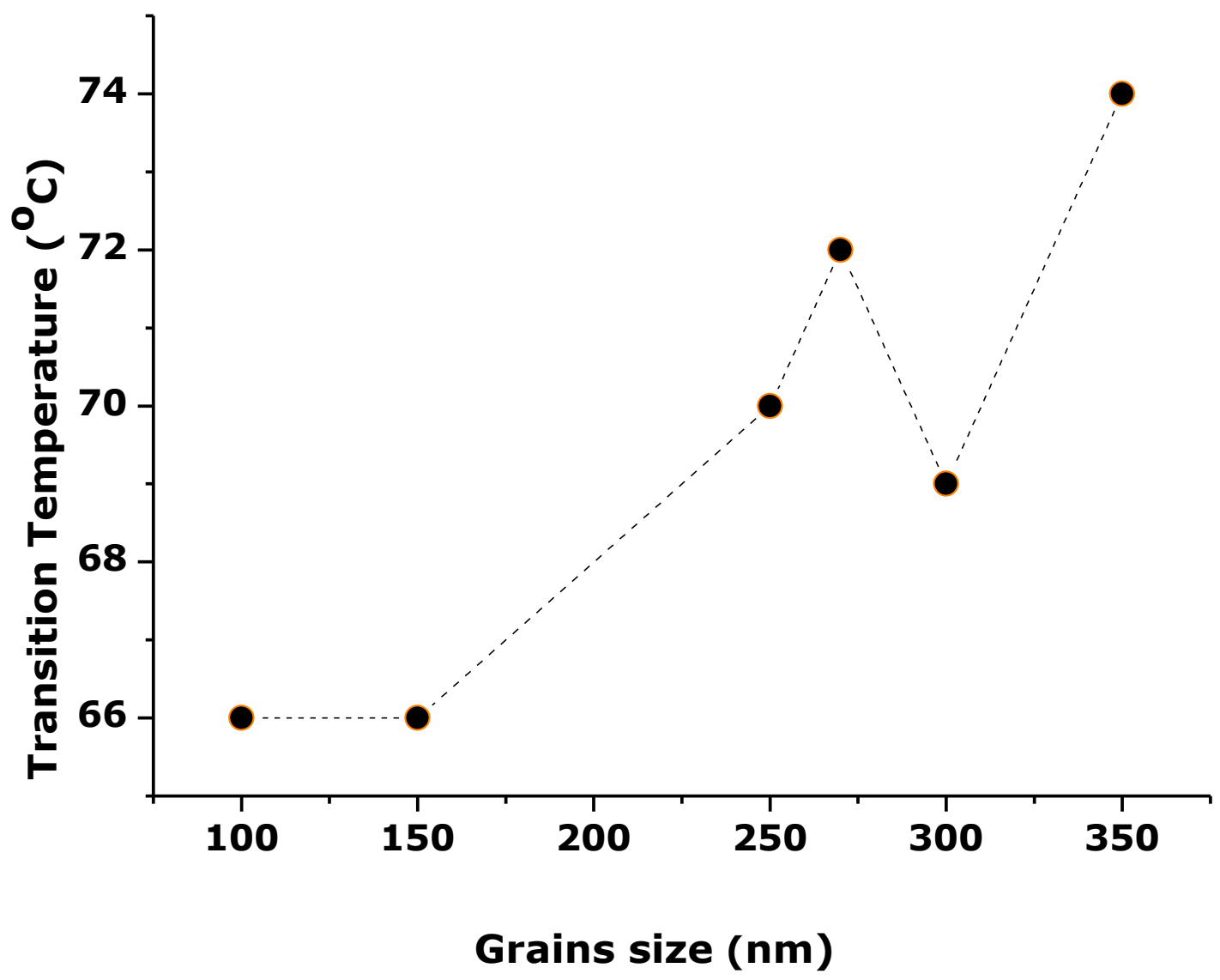

Fig.3c:

Variation of transition temperature of pulsed laser deposited $\mathrm{VO}_{2}$ thin films as function grains sizes obtained from SEM images (Fig.3). 


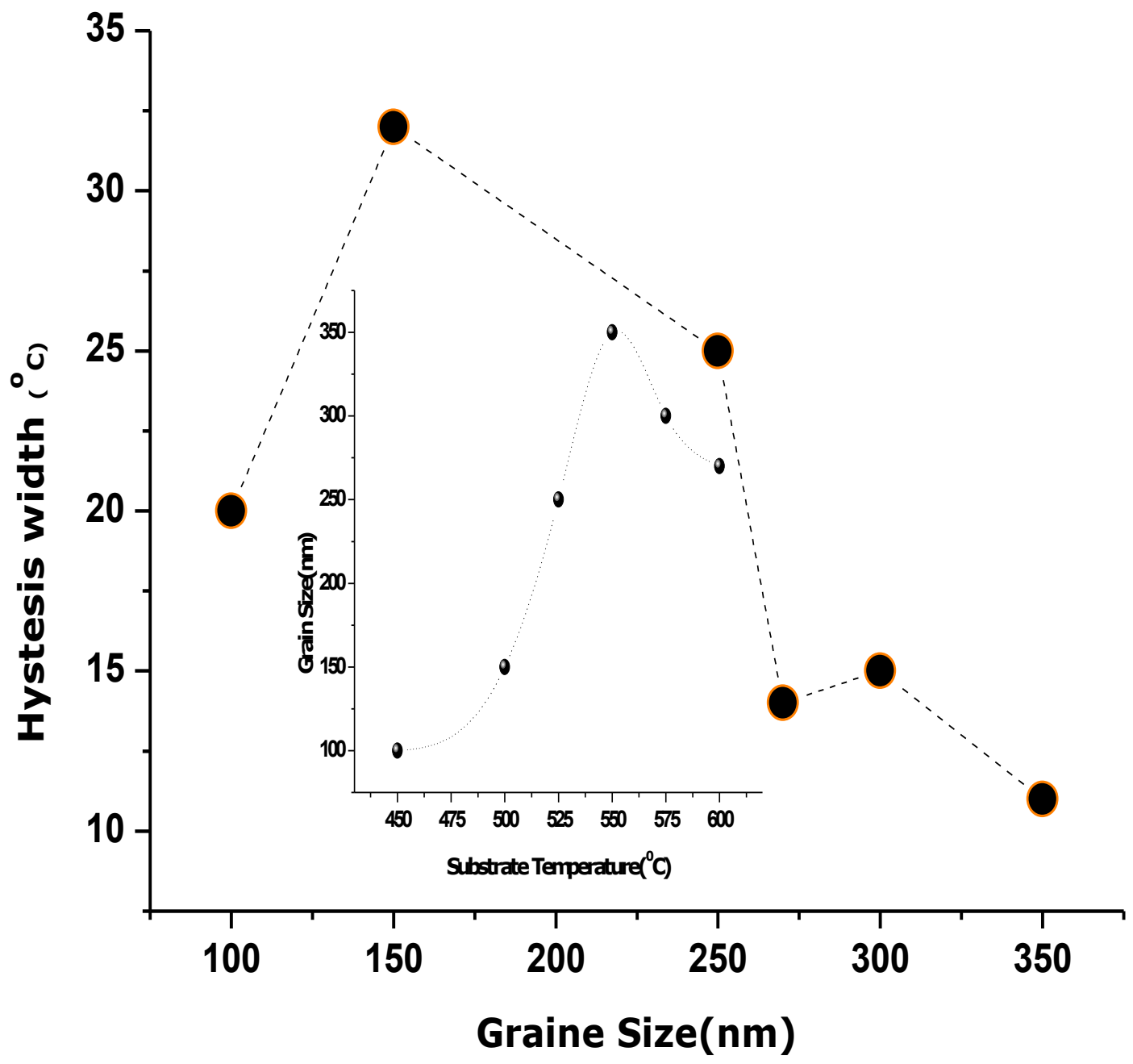

Fig.3d: Variation of hysteresis width of pulsed laser deposited $\mathrm{VO}_{2}$ thin films as function grains sizes Inset: Evolution of the grains sizes as function of substrate deposition temperature

at different temperatures and the average grains size was obtained from the SEM images using image-J sofware. Fig 3a shows the thermal hysteresis loops of the optical transmittance $\left(\mathrm{T}_{\mathrm{r}}\right)$ at a fixed wavelength of $1100 \mathrm{~nm}$ for $\mathrm{VO}_{2}$ thin films deposited at different temperatures. We see qualitatively different hysteresis shapes for the films deposited with different substrate temperatures as shown in Fig 3a. The transition temperature during heating $\left(\mathrm{T}_{\mathrm{H}}\right)$ or cooling $\left(\mathrm{T}_{\mathrm{C}}\right)$ is defined by the minimum of derivative Tr curve. The transition temperature of the films is defined as the average of transition temperature of the heating and the cooling; $\mathrm{T}_{\mathrm{MIT}}=\left(\mathrm{T}_{\mathrm{H}}+\mathrm{T}_{\mathrm{C}}\right) / 2$, while the hysteresis width $(\Delta T)$ is defined as the absolute difference between the $T_{c}$ and $T_{H}$. The results obtained for the transition temperature and the hysteresis loop, are plotted respectively in Fig $3 \mathrm{~b}$ and Fig $3 \mathrm{c}$ as function of the 

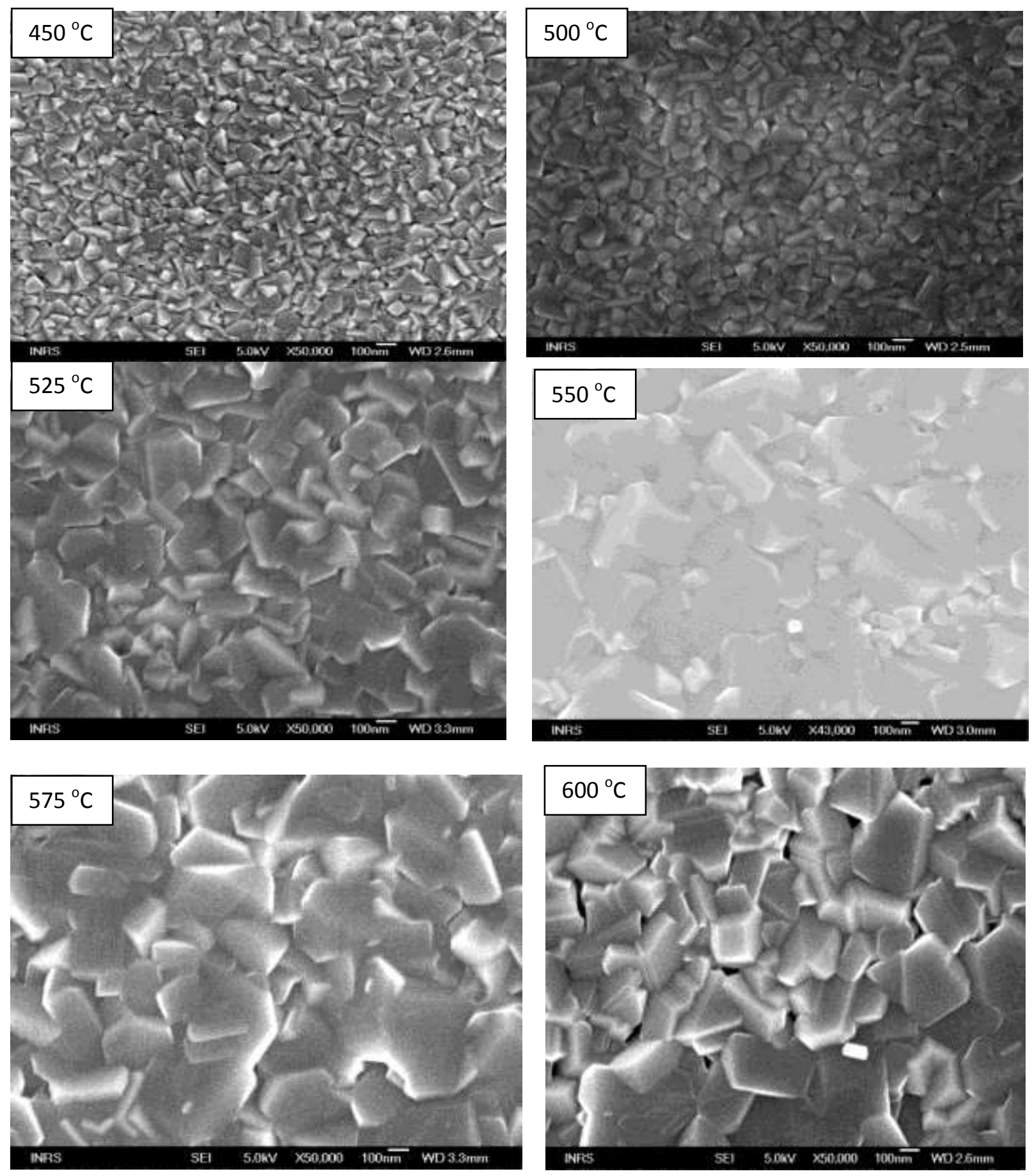

Fig.4:

SEM images of pulsed laser deposition $\mathrm{VO}_{2}$ as function of deposition temperature. 
average grains size obtained from SEM images. In Fig.4 we report on the 2D SEM images surface of the $\mathrm{VO}_{2}$ thin films deposited with different substrate temperature. As shown in the inset of Fig $3 \mathrm{c}$, the average grains size obtained from SEM images, increase with the deposition substrate temperature from $450{ }^{\circ} \mathrm{C}$ to $550{ }^{\circ} \mathrm{C}$ and drops at substrate temperature beyond $550{ }^{\circ} \mathrm{C}$ substrate deposition temperature.

Table 1: Variation of the Transition temperature during the heating $\left(\mathrm{T}_{\mathrm{H}}\right)$ and cooling $\left(\mathrm{T}_{\mathrm{C}}\right)$ of pulsed laser deposed VO $\mathrm{O}_{2}$ thin

\begin{tabular}{|l|l|l|l|l|l|l|}
\hline \multicolumn{2}{|c|}{ films as function of substrate deposition temperature. } \\
\begin{tabular}{|l} 
Substrate \\
Temperature \\
$\left({ }^{\circ} \mathrm{C}\right)$
\end{tabular} & 450 & 500 & 525 & 550 & 575 & 600 \\
\hline $\mathrm{T}_{\mathrm{H}}\left({ }^{\circ} \mathrm{C}\right)$ & 76 & 82 & 82 & 79 & 76 & 79 \\
\hline $\mathrm{T}_{\mathrm{C}}\left({ }^{\circ} \mathrm{C}\right)$ & 56 & 50 & 57 & 68 & 61 & 65 \\
\hline
\end{tabular}

From Table 1, we can see that the $\mathrm{T}_{\mathrm{H}}$ for all the samples is quite lager than to that of bulk single-crystal $\mathrm{VO}_{2}$. However, all the tree samples prepared at substrate temperature between $450{ }^{\circ} \mathrm{C}$ and $525{ }^{\circ} \mathrm{C}$, show a very large $\Delta \mathrm{T}$ because their $\mathrm{T}_{\mathrm{C}}\left(50-57^{\circ} \mathrm{C}\right)$ in addition to their higher $\mathrm{T}_{\mathrm{H}}$, are far lower than that of bulk $\mathrm{VO}_{2}$. As reported in Fig $3 b$ the transition temperature increases with the increase in grains size and drops at a grains size of 300 $\mathrm{nm}$ corresponding to the sample grown at a substrate temperature of $575{ }^{\circ} \mathrm{C}$ and then increase again. It is interesting to notice that, the obtained values for the transition temperature for the samples prepared at substrate temperature between $450{ }^{\circ} \mathrm{C}$ and $525{ }^{\circ} \mathrm{C}$ are similar to the value of bulk single crystal of $\mathrm{VO}_{2}$, but for higher substrate temperature from $550{ }^{\circ} \mathrm{C}$ to $600{ }^{\circ} \mathrm{C}$ there is a shift towards a higher temperatures with an exception for the sample grown at a substrate temperature of $575{ }^{\circ} \mathrm{C}$, which its transition temperature correspond almost exactly to the transition temperature of the single crystal of $\mathrm{VO}_{2}$.

J B Kana Kana et al [20] have reported high substrate temperature induced anomalous phase transition temperature shift in sputtered $\mathrm{VO}_{2}$ thin films on corning glass. They have observed an increase in the transition temperature from 70 to $80{ }^{\circ} \mathrm{C}$ when the substrate temperature varies from 450 to $600{ }^{\circ} \mathrm{C}$. In their results, a the substrate temperature range of $450-500{ }^{\circ} \mathrm{C}$ led to a transition temperature of $70{ }^{\circ} \mathrm{C}$ similar to the bulk single crystal this is in agreement with our results. While a higher substrate temperature from 550 to $600{ }^{\circ} \mathrm{C}$ led to a transition temperature of $75{ }^{\circ} \mathrm{C}$ and $80{ }^{\circ} \mathrm{C}$, respectively and these values are closer to our reported values but a little bit higher and this may be due to the difference in glass substrate type used. As reported by J B Kana Kana et al [20], the major two effects that could led to this higher $\mathrm{VO}_{2}$ transition temperature are a slight stoichiometry deviation and or a possible diffusion of some element from the glass substrate to the films such as $\mathrm{Al}, \mathrm{Na}$ or $\mathrm{Ca}$. As suggested from the XRD profile (Fig. 1), there may be a diffusion of $\mathrm{Na}$ in to the $\mathrm{VO}_{2}$ films 
and a formation of $\mathrm{N}_{1.80} \mathrm{~V}_{2} \mathrm{O}_{5}$ (400) (JCPDS 0020-1167), this would explain why we have observed higher transition temperature above a substrate temperature of $550{ }^{\circ} \mathrm{C}$, but does not account for the sample grown at a substrate temperature of $575{ }^{\circ} \mathrm{C}$. This anomaly seen for the sample of $300 \mathrm{~nm}$ of grains size corresponding to a substrate temperature of $575{ }^{\circ} \mathrm{C}$ in our results compared to the obtained trend by J B Kana Kana et al [20], may

be related to some effect induced by the substrate glass transition temperature reported to be around $575{ }^{\circ} \mathrm{C}$ during the growth of the films.

The increase of the hysteresis width in our samples as function of the grains sizes, is in agreement with the reported values by A. Ilinski et al [14] and J B Kana Kana [20] and R. Lopez et al [15], we notice an increase of hysteresis width from $20{ }^{\circ} \mathrm{C}$ to $32{ }^{\circ} \mathrm{C}$ for a grain size of $100 \mathrm{~nm}$ and $150 \mathrm{~nm}$ respectively and after that there is a continuous decrease of the hysteresis width with the increase in grains sizes that lead to a value of $11{ }^{\circ} \mathrm{C}$ for a grains size of $350 \mathrm{~nm}$ corresponding to the sample gown at a substrate temperature of $550{ }^{\circ} \mathrm{C}$. The decrease in Hysteresis width with the increase in grains sizes in our results agreed with the reported values [14, 20]. But it is quite interesting to see that the samples prepared at a substrate temperature range of $450-525{ }^{\circ} \mathrm{C}$ (specially for a substrate temperature of $500{ }^{\circ} \mathrm{C}$ corresponding to a grain size of $150 \mathrm{~nm}$ ), have a $\mathrm{T}_{\text {cooling }}$ lower than the other samples this explains why the hysteresis is larger. It have been reported that the thermo-optical properties of $\mathrm{VO}_{2}$ rise from the competing effect of grains sizes, dislocations, nucleation defects, grains boundaries and crystal imperfections. In previous studies in the literature, such low $\mathrm{T}_{\mathrm{C}}$ was also observed in $\mathrm{VO}_{2}$ films or particles with different morphologies. The isolated bar-like $\mathrm{VO}_{2}$ particles show a low $\mathrm{T}_{\mathrm{C}}$ of about $35{ }^{\circ} \mathrm{C}$ as reported by $\mathrm{R}$. Lopez et al [15] while individual spheroidal $\mathrm{VO}_{2}$ nanoparticle shows a $\mathrm{T}_{\mathrm{C}}$ that is as low as $25^{\circ} \mathrm{C}$ and misshapen $\mathrm{VO}_{2}$ nanoparticle with the same volume shows a $\mathrm{T}_{\mathrm{C}}$ of about $50{ }^{\circ} \mathrm{C}$ in the work done by $\mathrm{E}$. $\mathrm{U}$. Donev et al [21]. Porous nanostructured $\mathrm{VO}_{2}$ films obtained by $\mathrm{Y} . J . \mathrm{Xu}$ et al [22] show a low $\mathrm{T}_{\mathrm{C}}$ in the range of 38.5-43.2 ${ }^{\circ} \mathrm{C}$ while $\mathrm{VO}_{2}$ films with the "flower" like microstructure deposited on $\mathrm{Nb}$-doped $\mathrm{SrTiO}_{3}$ substrate by Y.J. Cui et al [23] shows a $\mathrm{T}_{\mathrm{C}}$ of about $54.5{ }^{\circ} \mathrm{C}$. The low $\mathrm{T}_{\mathrm{C}}$ of $\mathrm{VO}_{2}$ films indicates that the MIT upon cooling undergoes a significant lagging. In other words, as reported also by H. Zhang et al [24], the deposited films would require large additional driving forces in order to change from tetragonal to monoclinic phase. This could be attributed to the lack of nucleating defects and the large interfacial energies, which are determined by the characteristics of the particles in the deposited films, namely the small grain size resulting from low substrate deposition temperature. The smaller the grain size, the smaller the density of nucleating defects [24-26]. 


\section{Conclusion}

$\mathrm{VO}_{2}$ thin films were deposited on soda lime glass substrate by pulsed laser deposition. The effect of the substrate temperature during deposition on the structure and the metal insulator transition were systemically investigated by means of XRD, SEM and UV-Vis spectrophotometer. It was found that the temperature of the substrate influence, the structure, the morphology evidently and consequently the Metal-Insulator phase transition. When substrate temperature was $550{ }^{\circ} \mathrm{C}$, a change in $\mathrm{VO}_{2}(100)$ preferential orientation could be obtained. Interestingly a larger $\Delta \mathrm{T}$ was obtained for a grain size of $150 \mathrm{~nm}$ for the sample prepared at a substrate temperature of $500{ }^{\circ} \mathrm{C}$ and this was explained as a result of low transition temperature when the film have to go under crystallographic phase transition from tetragonal to monoclinic. This could be attributed to the lack of nucleating defects and the large interfacial energies, which are determined by the characteristics of the particles in the deposited films, namely the small grain size resulting from low substrate deposition temperature.

\section{References}

[1] Xiaofeng Xu, Xinfeng He, Haiyang Wang, Quanju Gu, Shuaixu Shi, Huaizhong Xing,Chunrui Wang, Jing Zhang, Xiaoshuang Chen, Junhao Chu. Applied Surface Science 261(2012) 83-87

[2] L.T.Kang,Y.F. Gao, Z.T. Zhang,J.Du,C.X.Cao,Z.Chen,H.J.Luo, Journal of Physical Chemistry C 114 (2010) 1901-1911.

[3] W.Hong-chen,Y.Xin-Jin, L Jiang -Jun,L.Yi.CHIN PHY.LETT, Vol.22,No.7 (2005)1746.

[4] J. B. Goodenough, J. Solid State Chem. 3, 490 1971

[5] V.A.Klimov, I.O.Timofeeva, S.D.Khanin,E.B.Shadrin,A.V.Ilinskil,F.Silva-Andrade,Technical Physics 47 (9) (2002) 1134-1139.

[6] J.B. Kana Kana, J.M. Ndjaka, P. Owono Ateba, B.D. Ngom, N. Manyala, O. Nemraoui, A.C. Beye, M. Maaza, Appl. Surf. Sci. 254 (2008) 3959-3963.

[7] M. Maaza, K. Bouziane, J. Maritz, C. Sella \& J.M. Frigerio, Opt. Mater. 15 (2000) 41-45.

[8] G. Guzman, R. Morineau, J. Livage, Mater. Res. Bull. 29 (1994) 509-515.

[9] M.B. Sahana, M.S. Dharmaprakash, S.A. Shivashankar, J. Mater. Chem. 12 (2002) 333-338.

[10] P. Jin and S. Tanemura, Jpn. J. Appl. Phys. 33 (1994) 1478-1483.

[11] M. Nagashima and H. Wada, Thin Solid Films 312 (1998) 61-65.

[12] Landbolt-Bornstein Series, "Physical-Chemical Properties of Vanadium and Related Oxides", (1998).

[13] C.H. Griffits and H.K. Eastwood, J. Appl. Phys. 45 (1974) 2201-2206.

[14] A.Ilinski, F.Silva-Andrade, E. Shadrin, V.Klimov, Journal of Non-Cristalline Solids 338-340 (2004) 266-268.

[15] R. Lopez, L. A. Boatner, T. E. Haynes. Applied Physics Letters, 79 (2001) 3161-3163.

[16] T. W. Chui, K. Tonooka, N. Kikuchi. Appied Surface Science 256 (2010) 6834-6837. 
[17] H. Zhou, M. F. Chisholm, Tsung-Han Yang, S. J. Pennycook, and J. Narayan J. Appl. Phys. 110, 073515 (2011)

[18] Songwei Lu, Lisong Hou, Fuxi Gan, Thin Solid Films 353 (1999) 40-44

[19] Wang Xue-Jin, Liang Chun-Jun, Guan Kang-Ping, Li De-Hua, Nie Yu-Xin, Zhu Shi-Oiu, Huang Feng, Zhang Wei-Wei and Cheng Zheng-Wei' Chinese Phys. B 17 (2008) 3512

[20] J.B. Kana Kana, J.M. Ndjaka, B.D. Ngom, A. Y. Fasasi, O. Nemraoui, R Nemutudi, D. Knoesen and M. Maaza. Optical Materials 32 (2010) 739-742

[21] E. U. Donev, R. Lopez, L. C. Feldmant, R. F. Haglund, NanoLetters 9 (2009) 702.

[22] Y.J. Xu, W.X. Huang, Q.W. Shi, Y. Zhang, Y.B. Zhang, L.W. Song, Y.X. Zhang, Applied Surface Science 259 (2012) 256.

[23] Y.J. Cui, X. W. Wang, Y. Zhou, R. Gordon, S. Ramanathan, Journal of Crystal Growth 338 (2012) 96.

[24] H. Zhang, Zhiming Wu, Qiong He, Yadong Jiang, Appl. Surf. Sci. (2013), http://dx.doi.org/10.1016/j.apsusc.2013.04.028

[25] J.Y. Suh, R. Lopez, L.C. Feldman, R. F. Haglund, Journal of Applied Physics 96 (2004) 1209.

[26] R. Lopez, T.E. Haynes, L.A. Boatner, L.C. Feldman, R.F. Haglund Jr., Physical Review B 65 (2002) 224113. 